\title{
Towards Dynamic Assessment of Healthy Breast Skin Temperature using Infrared Thermography
}

\author{
by D. Marques*, J. Moreira* and R. Vardasca*,,**,** \\ * Faculdade de Engenharia, Universidade do Porto, Rua Dr. Roberto Frias 4200-465 Porto, Portugal, \\ ricardo.vardasca@gmail.com \\ ** INEGI, Rua Dr. Roberto Frias 400, 4200-465 Porto, Portugal \\ *** University of South Wales, Pontypridd, CF37 1DL, United Kingdom
}

\begin{abstract}
Arial, 9pt, bold)
Breast skin temperature assessment has been of interest since of the first application of Infrared Thermography in Medicine in 1956. Since it many investigations attempted to appraise the method as a screening tool, although reference data is still lacking and dynamic thermal imaging has proved its value in other clinical applications. It is aim of this research to apply a thermal stimulus to the breasts of 11 healthy participants through thermal conduction and convection to determine, which can be feasible in clinical setup for further research involving breast cancer patients. It was found that the use of a conduction stimuli on the nipple for a 1 minute to be the most adequate method.
\end{abstract}

\section{Introduction}

Breast screening with infrared thermography is as old as the first application of this imaging method in medicine. It has been extensively studied for its ability to detect breast neoplasms. It is intended to understand the relation between the thermal patterns of the skin surface and the underlying physiological or pathological parameters. Thermal variations on the breast surface can be considered a risk factor. This can lead to continuous monitoring of the patient regarding the discovery of possible breast malignancies.

Many of the studies on the use of Infrared Thermography in screening for breast cancer have a considerable number of participants. In addition, some of them monitored the patients for long periods of time [1-3], these authors have described that an abnormal breast thermogram is a significant indicator of biological risk, $\mathrm{Ng}$ [4] also mentioned it in his excellent review of the IRT as a non-invasive modality of breast cancer detection.

Dynamic Infrared Thermography (DIRT) implies an external thermal challenge and a behaviour of recovery. DIRT is based on the relationship between dermal perfusion and the rate of skin surface temperature variation, after external application of local thermal transient stimuli [5-7]. In this arena, Button et al. (2004) [8] has shown in an animal study that DIRT can detect breast malignancies through vasodilation caused by nitric oxide production by neoplastic lesions. Parisky et al. (2003) [9] studied the efficacy of DIRT in the detection of breast neoplasms, using prebiopsy patients. Through a cooling by convection currents, the author attempted to identify a breasts thermal pattern of previously diagnosed women. Their findings on 875 biopsied lesions showed that thermography had an over $95 \%$ predictive value and it was concluded that the infrared imaging was a safe non-invasive procedure that would be valuable adjunct to other medical imaging modalities, as mammography, in determining whether a lesion was benign or malignant. Unfortunately, the inferior IR equipment did not allow an even greater success of the study. However, as the years progress, there are improvements in technology, resulting in even better results.

Due to lack of studies, there is still no clear evidence about the role of DIRT as a complementary technique in breast cancer detection. However, it is known that this modality can be improved. Studies $[10,11]$ indicate that the use of texture features and support vector machine or three-dimensional close-actual-breast model with a numerical grid and tetrahedral elements increases the sensitivity and specificity of DIRT as a screening tool.

The purpose of this study is the definition of a DIRT methodology in asymptomatic women; validation of preselected breast regions of interest (ROI); and the study of three parameters influence (age, BMI and menstrual phase) on the breast temperature distribution.

The lack of dynamic studies in asymptomatic women has increased interest in this research.

\section{Methodology}

Eleven healthy women accepted to participate in this research through signing an informed consent, mean age 40 years (range: $22-54$ years) and mean BMl $24.12 \mathrm{~kg} / \mathrm{m}^{2}$ (range: $19.01-29.1 \mathrm{~kg} / \mathrm{m}^{2}$ ). The image recording took place during a week at every day's morning in a controlled environment room (mean temperature $22.0 \pm 1.0^{\circ} \mathrm{C}$ and $47.5 \pm 2.0 \%$ of relative humidity. All participants unclothed the breasts and acclimatized to room temperature for 10 minutes before the baseline image was taken using the FLIR E60 thermal camera (FPA size of $320 \times 240$, NETD of $<50 \mathrm{mK}$ at $30{ }^{\circ} \mathrm{C}$ and measurement uncertainty of $\pm 2 \%$ of the operating temperature range), being followed by a thermal challenge and for a set of 10 thermal images taken, 1 per minute, after the provocation test.

The thermal provocation tests were of two kinds: 
- $\quad$ Thermal conduction, using two aluminium discs $(5 \mathrm{~cm}$ diameter by $2 \mathrm{~cm}$ thick) at room temperature in contact with the breast nipple for 1 and 2 minutes.

- $\quad$ Thermal convection using two fans (20W) placed in front of each breast for 1, 2 and 5 minutes.

The images were loaded and analysed in the FLIR ThermaCAM Researcher Pro 2.10, using the 4 quadrants regions of interest (ROI) per breast (Fig. 1), from which the mean temperature was recorded.
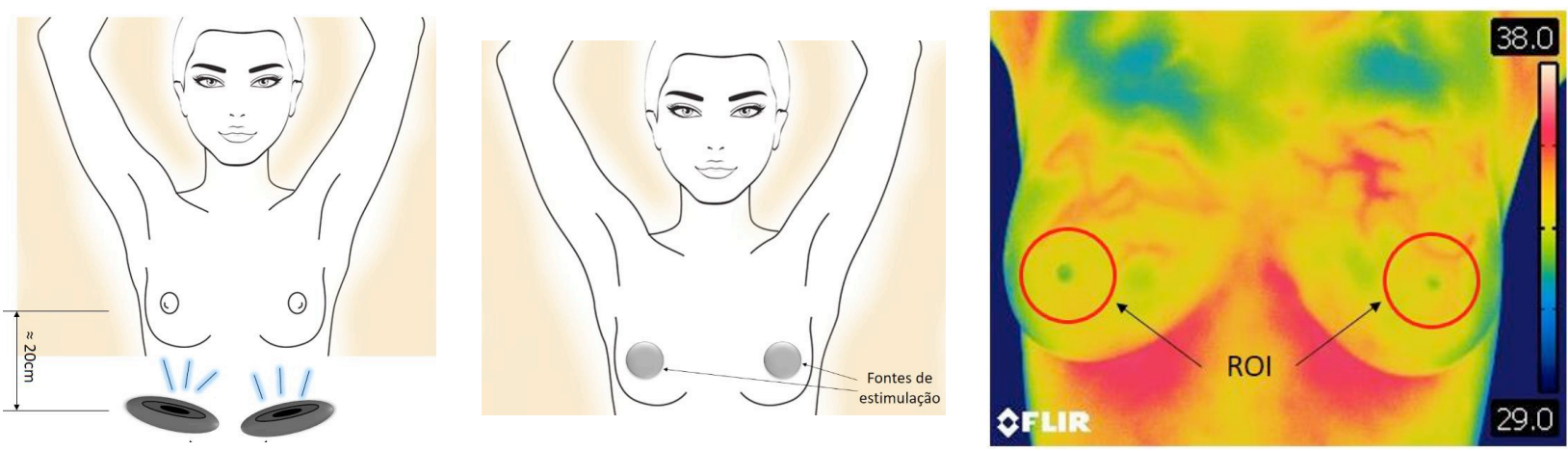

Fig. 1. Provocation tests, left: fan and center: aluminum discs and the regions of interest (right).

\section{Results}

Comparing both provocation methods and their variants (Fig. 2), it can be observed that the aluminium discs for 1 minute in contact with the breast nipple showed the best recovery curve and took less examination time.
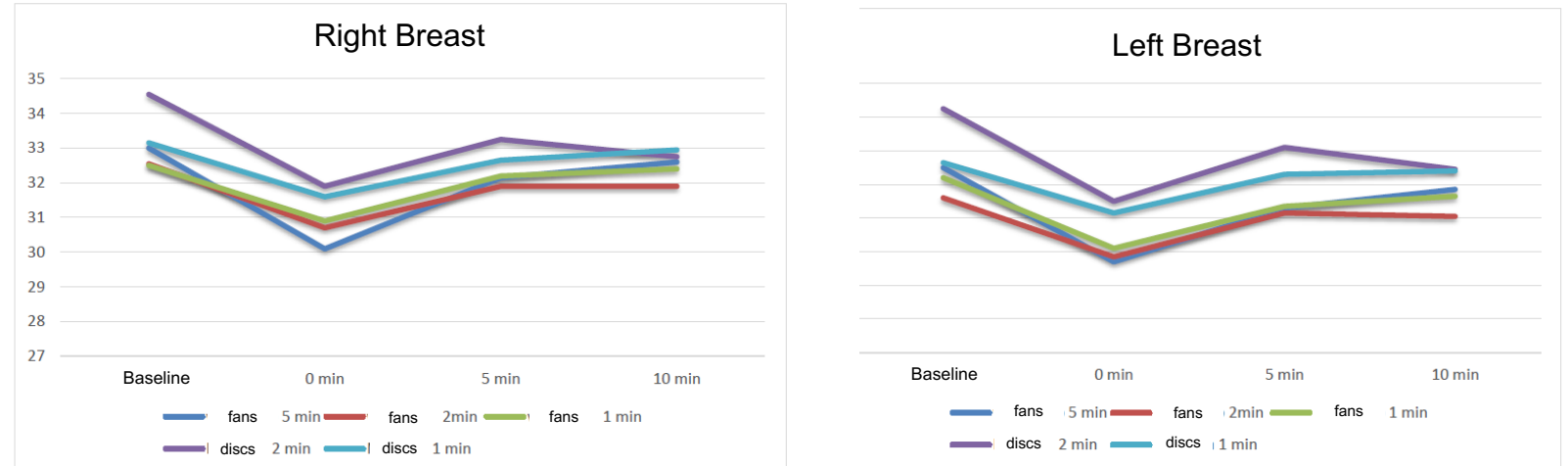

Fig. 2. Average results for the right (left) and left (right) breasts for the 5 different tests using the 2 provocation methods.

\section{Discussion and Conclusion}

One of the limitations in implementing DIRT in clinical practice can be the time needed to do an examination, being the conduction test for one minute, that who showed the best recovery pattern, counting the acclimatization period, the provocation and the stimuli recovery time, the whole examination would take around 23 minutes, which is feasible. Also the conduction test was found to be more reproducible and easy to implement than the convection one, which would cause more variation on different size breasts.

It is important to bear in mind that some factors may influence the breasts superficial temperature, namely the phase of the menstrual cycle. In this way, it is necessary to know better its impact on the distribution of surface temperature and in a more detailed breast regions of interest. Although DIRT may add more thermal information useful for physiological characterization of patients than a simple thermal examination.

\section{ACKNOWLEDGEMENTS}

The authors would like to thank the funding of the project LAETA - UID/EMS/50022/2013. 


\section{REFERENCES}

[1] Spitalier, H., Giraud, D. et al., Does infrared thermography truly have a role in present-day breast cancer management? Biomedical Thermology, Alan R. Liss, New York, NY, 269-278, 1982.

[2] Gros, C., Gautherie, M., Breast thermography and cancer risk prediction. Cancer, 45, 51, 1980.

[3] Louis, K., Walter, J., Gautherie, M., Long-term assessment of breast cancer risk by thermal imaging, in Biomedical Thermology. Alan R. Liss Inc., 279-301, 1982.

[4] Ng, E. Y. K. A review of thermography as promising non-invasive detection modality for breast tumor, International Journal of Thermal Sciences, 48, 849-859, 2009.

[5] Francis, J. E., Roggli, R., Love, T.J. Thermography as a means of blood perfusion measurements. J Biomech Eng ,101, 246-249, 1979.

[6] Wilson, S. B., Spence, V. A. Dynamic thermographic imaging method for quantifying dermal perfusion: potential and limitations. Med Biol Eng Comput, 27, 496-501, 1989.

[7] Boe Setså, L., Mercer, J. B., de Weerd, L., Elveness, O.P. Dynamic Thermography as a reliable, non-invasive and easy method for monitoring perfusion in free flap surgery, preliminary results. Thermology International, 15 , 75, 2005.

[8] Button, T. M., Li, H., Fisher, P., Rosenblatt, R., Dulaimy, K., Li, S., O’Hea, B., Salvitti, M., Geronimo, V., Geronimo, C., Jambawalikar, S., Carvelli, P., Weiss, R. Dynamic infrared imaging for the detection of malignancy. Physics in Medicine and Biology, 49, 3105-3116, 2004.

[9] Parisky Y. R., Sardi A., Hamm R., Hughes K., Esserman L., Rust S., Callahan K. Efficacy of computerized infrared imaging analysis to evaluate mammographically suspicious lesions. American Journal of Roentgenology, 180, 263-269, 2003.

[10] Acharya, U. R., Ng E. Y. K., Tan, J. H., et al. Thermography based breast cancer detection using texture features and Support Vector Machine. J Med Syst, 36:1503-10, 2012.

[11] Ng, E. Y. K., Sudharsan, N. M. Computer simulation in conjunction with medical thermography as an adjunct tool for early detection of breast cancer. BMC Cancer 4, 17, 2004. 